Research Article

\title{
Improvement of Stop-Hole Method on Fatigue-Cracked Steel Plates by Using High-Strength Bolts and CFRP Strips
}

\author{
Xu Jiang $\mathbb{D}^{1},{ }^{1}$ Zhilin Lv $\left(\mathbb{D},{ }^{1}\right.$ Xuhong Qiang $\mathbb{D}^{2},{ }^{2}$ and Jiandong Zhang $\mathbb{D}^{3}$ \\ ${ }^{1}$ Department of Bridge Engineering, College of Civil Engineering, Tongji University, Shanghai, China \\ ${ }^{2}$ Department of Structural Engineering, College of Civil Engineering, Tongji University, Shanghai, China \\ ${ }^{3}$ JSTI Group, Nanjing, China
}

Correspondence should be addressed to Xuhong Qiang; qiangxuhong@tongji.edu.cn

Received 20 October 2020; Revised 24 January 2021; Accepted 29 January 2021; Published 11 February 2021

Academic Editor: Raffaele Landolfo

Copyright $(92021 \mathrm{Xu}$ Jiang et al. This is an open access article distributed under the Creative Commons Attribution License, which permits unrestricted use, distribution, and reproduction in any medium, provided the original work is properly cited.

\begin{abstract}
Steel bridges are extremely damaged by fatigue subjected to cycling load. Therefore, it is often necessary to put forward effective reinforcement to strengthen steel structures during the daily maintenance. In this study, two repairing methods of high-strength bolts and high-modulus CFRP strips on the basis of stop-hole repair method were introduced, respectively, to investigate fatigue improvement of cracked steel plates. First of all, numerical analysis was conducted to predict the repair efficiency and investigate the optimal parameters of each method. Variables studied were stop-hole diameter, pretightening force of bolt, and size of CFRP patch. Subsequently, a total of 12 specimens were tested to study the repairing efficiency of cracked steel plates with various strengthening methods through cyclic loading. At the same time, the failure mode and fatigue life were analyzed to present the improvement of fatigue performance. In addition, the experimental results were compared against the S-N curves of this strengthened fatigue detail. The outcomes of this study revealed that an improvement in the influence of fatigue-crack repair with the adoption of these two strengthening methods was evident. Numerical results showed that the addition of these materials could significantly diminish stress concentration factor around hole edge and improve their fatigue performance in comparison with only stop-hole method. Fatigue test results indicated that the crack initiation life of specimens repaired by stop-hole method was more than 20 times that of the unrepaired specimens. The high-strength bolt reinforced stop hole and CFRP patched stop hole can extend the crack initiation life by 9 and 8 times, respectively, in contrast to control specimens with sole stop-hole method. Finally, it was demonstrated that repairing damaged steel plates with stop-hole method alone was not enough to satisfy the fatigue strength requirements of various countries. But the fatigue strength category of damaged steel plates after further repairing with highstrength bolts and high-elastic-modulus CFRP, respectively, was higher than category A of AASHTO.
\end{abstract}

\section{Introduction}

A number of steel bridges built in earlier ages are still in existence and in service. However, with ever-increasing traffic volumes and required extension of the service life of steel bridges, fatigue cracks are prone to appear, especially at welded connections of orthotropic steel bridge decks [1]. In order to reduce the damage of fatigue cracks, it is of great significance to conduct fatigue strengthening in order to eliminate fatigue cracks or retard further crack propagation in addition to early preventive maintenance. The traditional repairing methods of steel structures include stop-hole method, rewelding, and new plate attachment/replacement, while these methods might not be feasible in all cases. Among them, the stop-hole method, as a temporary or emergency treatment, can effectively repair fatigue cracks caused by stress concentration at the tip of cracks and thus extend the fatigue life of cracked structural components [2-4]. However, due to the drilling defects and new stress concentration region around the stop hole, the cracks may generate again from the edge of hole during a relatively short time [5]. In order to improve the crack arrest behavior of drilling holes, a considerate number of experimental studies with respect to fatigue crack arresting and repairing were presented in recent decades. Many researchers had analyzed the relevant parameters such as reasonable hole diameter 
$[6,7]$, hole position $[8,9]$, hole shape [10], and additional hole arrangement method [11], but these are studied by all kinds of loading models that cannot be directly applied in steel bridges because of the different material properties. A double stop-hole method proposed by Razavi et al. [12] can reduce the stress level around the hole to extend more fatigue life than that of common single stop-hole method, yet potential risk of structure failure will exist due to weakening of section stiffness. In terms of assistant operation of stop holes, Duprat et al. [13] proposed the stop-hole method to repair fatigue cracks, and adopting cold expanded hole method or inserting interference fit fastener can effectively delay second-time fatigue crack initiation. Furthermore, employing high-strength bolts for the stop-hole method can reduce the peak stress near the stop hole through the pretightening pressure for enhancement of repair effectiveness [14]. However, there were few data available about fatigue improvement achieved by combining stop hole with highstrength bolts.

Carbon fiber reinforced polymers (CFRP), recognized as an advanced composite material, possess excellent mechanical properties, such as high strength-to-weight ratio, good antifatigue performance, and convenience of installation. Because of those excellent properties, the method using CFRP for retrofitting aging metallic structures is a research hotspot developed in recent years $[15,16]$. For example, the old metal riveted structures can be retrofitted by means of externally bonded CFRP. In [17], the authors focused on the lap shear tests on hot-driven riveted connections strengthened by CFRP, which demonstrated the efficacy as a repair material. Furthermore, the majority of existing studies confirmed that crack growth can be prevented by directly covering the crack area of steel plate with carbon fiber reinforced polymers under the cyclic loading [18-20]. For the sake of promoting the effectiveness of the repair, CFRP materials can be utilized to strengthen the sole single drilling-hole method [21]. It is a promising method to eliminate crack tip by drilling hole and then lessen the stress around the hole edge of steel plates strengthened by CFRP.

In this paper, two kinds of strengthened stop-hole methods, the high-strength bolt reinforced stop-hole method and the CFRP patched stop-hole method, were investigated and compared. Firstly, the stress variation of $12 \mathrm{~mm}$ thick cracked steel plates affected by the key repair parameters was analyzed by finite element method. On this basis, a series of experimental tests were conducted to determine the fatigue enhancement with various strengthening method through cyclic loading. Besides, the test values of repaired groups were compared against the fatigue strength curves.

\section{Specimen Design and Numerical Simulation}

2.1. Specimen Preparation. In order to investigate the crack propagation of steel bridge plates and subsequent repair tests, the thickness of specimens is $12 \mathrm{~mm}$, which has the common thickness of the diaphragms or crossbeams used in steel bridges. The dumbbell-shaped specimens, with dimensions of $620 \times 230$ (length $\times$ width), were designed and prepared in a similar way, as illustrated in Figure 1. Each specimen has an initial damage composed of a $16 \mathrm{~mm}$ long notch and a $14 \mathrm{~mm}$ long artificial precrack in the middle of the long edge. Then the cracked steel plates were repaired on the damage area using various methods to enhance the fatigue life. Figure 2 shows the repair scheme of specimens, including (1) specimens repaired by only the stop-hole method, (2) specimens repaired by the high-strength bolt stop-hole method, and (3) specimens repaired by highmodulus CFRP strips.

2.2. Material Properties. The retrofitting system mainly contains the three following main materials, namely, steel plate, CFRP strips, and structural adhesive. Table 1 lists all the material properties used in the FE modeling and experiments. The grade of utilized steel plates in all experiments was Q345. Furthermore, material experiments of three steel plates were conducted and mechanical properties were obtained. The experiments adopted the UT70-30 carbon fiber cloth produced by Japan Toray Industries, and the material properties of the structural adhesive were provided by the manufacturer.

\subsection{FE Modeling and Analysis}

2.3.1. Modeling Description. To obtain the optimal configuration of repair test, numerical models were established to study the effect of repair key parameters on the stress distribution of steel plates. Figure 3 shows the unrepaired model and mesh of crack tip set up by FEM software ABAQUS. All the models of steel plates adopted solid C3D8R elements, and crack tip was meshed with 6-node linear triangular prism elements (C3D6). The artificial precrack was created by assigning seam in the software. The global element size was $2 \mathrm{~mm}$, but, for local area of crack, the finite element mesh was finely divided to $0.5 \mathrm{~mm}$. Taking into account the actual loading in the experiment, during the modeling process, the actual clamping surface of $55 \mathrm{~mm} \times 45 \mathrm{~mm}$ above is constrained to the displacement in the $x, y$, and $z$ directions, and the surface traction-shear load of $60 \mathrm{kN}$ is applied to the actual clamping surface of $55 \mathrm{~mm} \times 45 \mathrm{~mm}$ below, which makes the steel plate in a tension state.

Figure 4 manifests the finite element models of various strengthening methods. For stop-hole model (Model 1), the center of crack stop hole was set at the crack tip. Besides, boundary conditions and load conditions were identical to the unrepaired model. In Model 2, considering that the bolt plays the role of connection and fastening, for the purpose of simplicity, the friction coefficient between the bolt gasket and steel plate was not considered for the time being. The high-strength bolt adopted beam element to model and used the MPC beam to transfer the pretightening force imposed by bolt load to the area of gasket. The other conditions of Model 2 were the same as those of the crack arrest hole model. For the high-modulus CFRP repair model, CFRP strips were pasted at the crack areas on both sides of the steel plates based on Model 1. The patch consisted of 10 layers of 


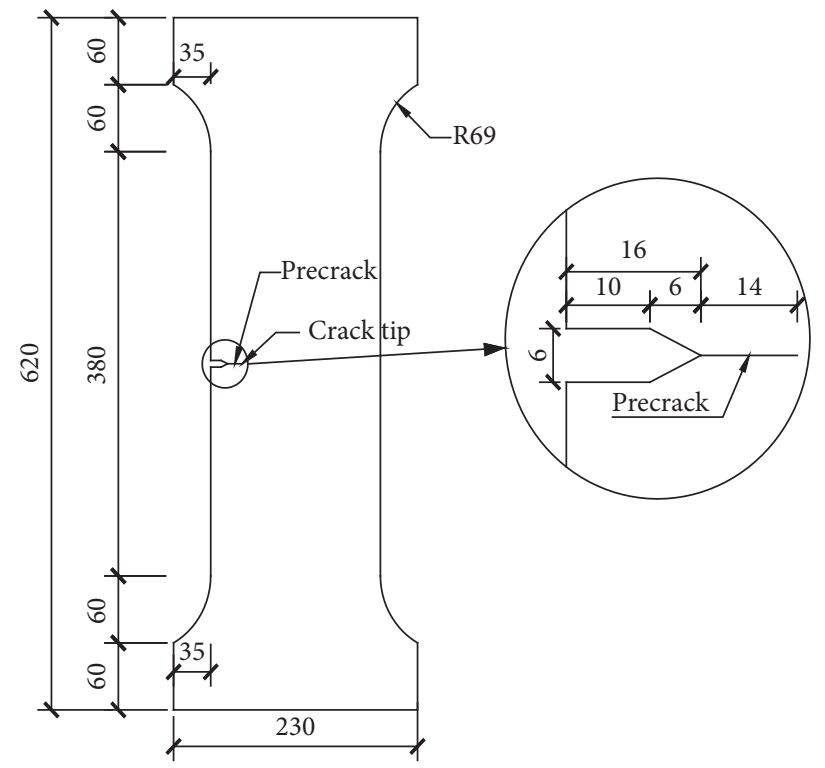

FIgURE 1: Dimensions of the specimen and damage $(\mathrm{mm})$.

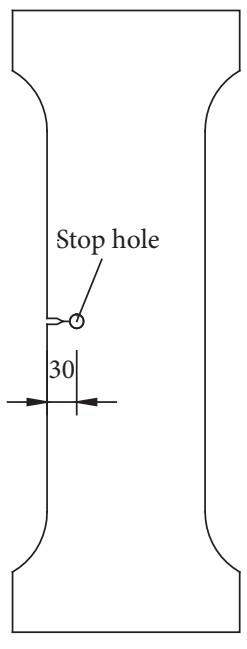

(a)
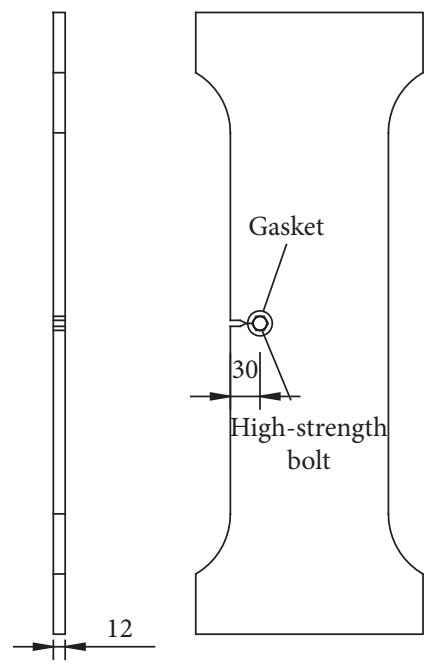

(b)
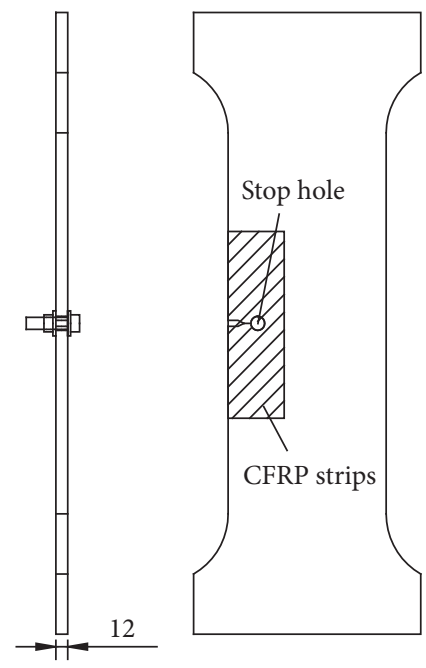

(c)

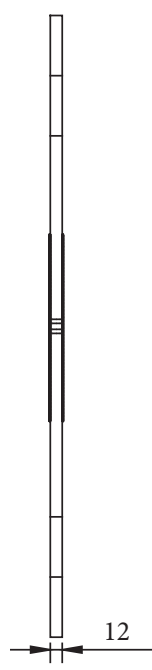

Figure 2: Dimensions of strengthened steel plates with various repair methods (mm). (a) Stop-hole repair group. (b) High-strength bolt stop-hole group. (c) Highmodulus CFRP repair group.

TABLE 1: Material properties in the test.

\begin{tabular}{lccc}
\hline Property & Steel plate & UT70-30 CFRP & Adhesive \\
\hline Thickness $(\mathrm{mm})$ & 12 & 0.167 & 0.55 \\
Yield strength $(\mathrm{MPa})$ & 418 & - & - \\
Tensile strength $(\mathrm{MPa})$ & 541 & 4216 & 53.1 \\
Young's modulus $(\mathrm{GPa})$ & 2.105 & 252 & 2.49 \\
Poisson's ratio & 0.3 & 0.3 & 0.3 \\
Shear modulus $(\mathrm{GPa})$ & - & 13 & - \\
\hline
\end{tabular}




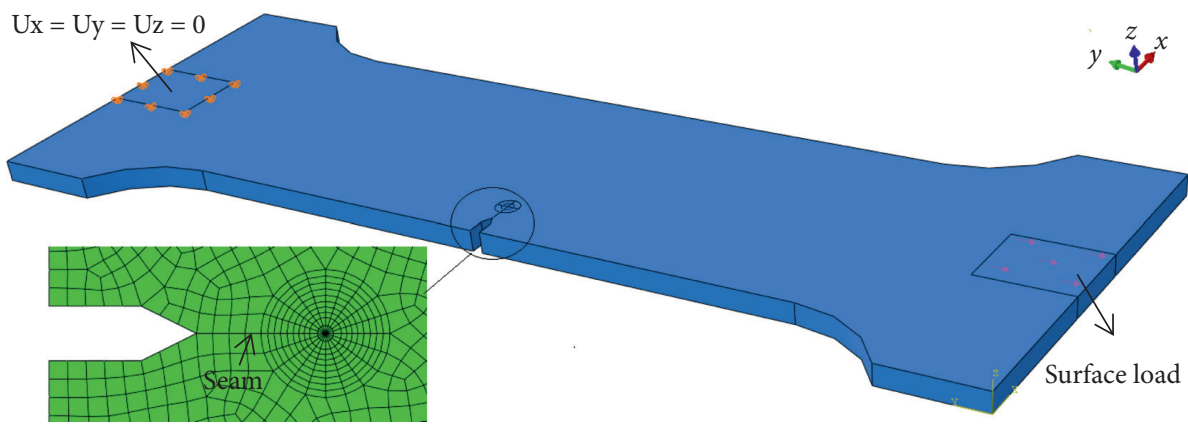

FIGURE 3: Numerical model of specimens without repairing.

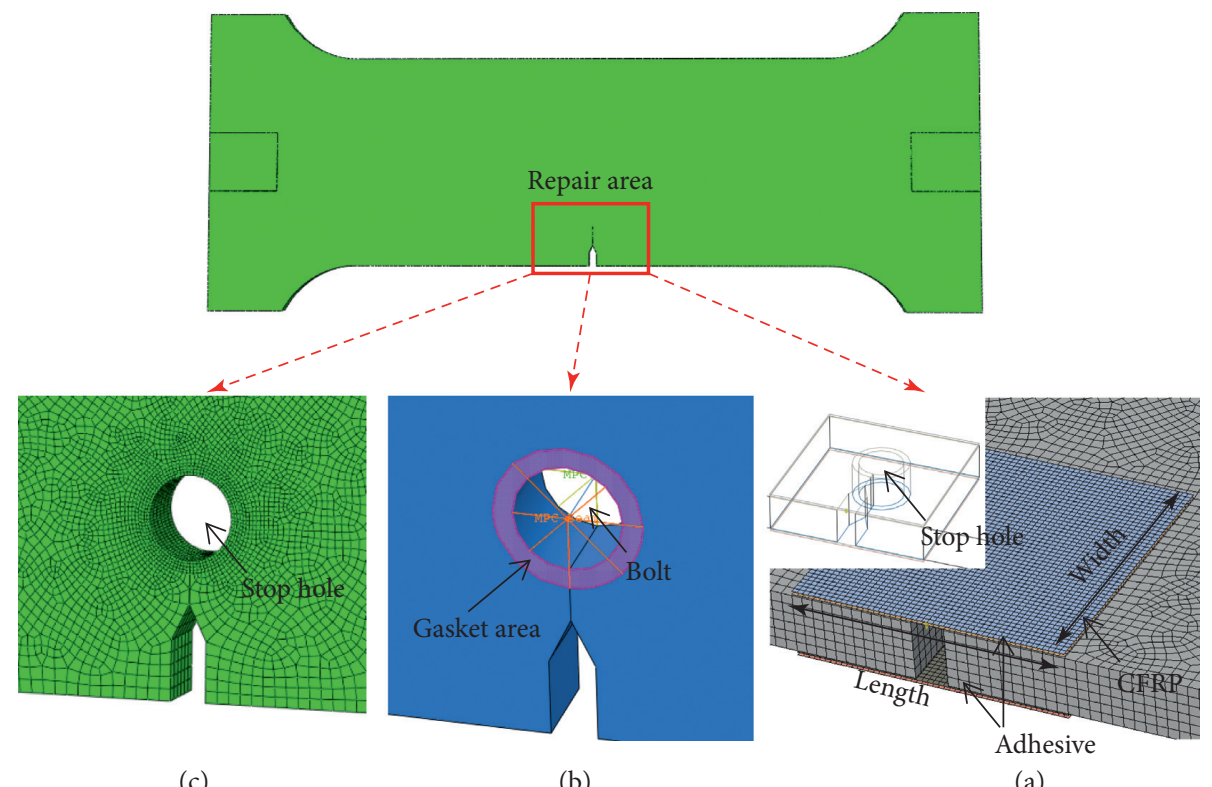

FIgURE 4: Numerical models of various strengthening method. (a) Model 1. (b) Model 2. (c) Model 3.

CFRP cloth with the fiber direction perpendicular to the crack. The CFRP strips were meshed with conventional shell element (S4R) created by "composite-layup" in ABAQUS and the adhesive was also modeled by S4R element. In general, it is assumed that CFRP strips and steel plate are firmly bonded in the finite element model and the components are in the linear elastic stage during fatigue loading. Consequently, the "tie" constraint was used between the CFRP-adhesive and adhesive-steel plate interfaces, which coordinated displacement and stress in the interfaces. All the material properties used in the modeling are in agreement with Table 1 . The optimal parameters of each method were investigated by finite element analysis. The parameters mainly include the crack stop-hole diameter, the level of pretightening force, and the size of CFRP strips.

2.3.2. The Influence of Hole Diameter. Five finite element models of specimens with the diameters of $8 \mathrm{~mm}, 10 \mathrm{~mm}$, $14 \mathrm{~mm}, 18 \mathrm{~mm}$, and $22 \mathrm{~mm}$ are, respectively, established to optimize the dimensions of the stop hole. The maximum stress of steel plates under different hole diameter was calculated and the crack arrest effect of repaired steel plates was evaluated by stress concentration factor $\left(K_{\mathrm{t}}\right)$ and fatigue notch coefficient $\left(K_{\mathrm{f}}\right) . K_{\mathrm{t}}$ and $K_{\mathrm{f}}$ can be acquired from equations (1) and (2), respectively, where $\sigma_{\max }$ is the practical maximum stress obtained from finite element analytical results, $\sigma_{\text {nom }}$ is the nominal stress calculated by equations (3), and $c$ belongs to constant of material $(c=0.45$ for steel Q345) [22]; $\rho$ is the radius of stop hole. In equation (3), P refers to the load, and $\mathrm{W}$ is the width of the inner edge of the steel plate; $a$ is the length of the crack; $b$ is the length of the notch; $t$ is the thickness of the steel plate; $D$ is the diameter of the crack arrest hole.

$$
\begin{aligned}
K_{t} & =\frac{\sigma_{\text {max }}}{\sigma_{\text {nom }}}, \\
K_{f} & =1+\frac{K_{t}-1}{1+c / \rho}, \\
\sigma_{\text {nom }} & =\frac{P(2 a+2 b+D+W)}{t(W-a-b-D / 2)^{2}} .
\end{aligned}
$$

Table 2 lists the stress concentration coefficient and fatigue notch coefficient of stop-hole model under different 
TABLE 2: $K_{\mathrm{t}}$ and $K_{\mathrm{f}}$ of stop-hole model under different diameters.

\begin{tabular}{lcccc}
\hline Diameter $\mathrm{D} / \mathrm{mm}$ & $\sigma_{\mathrm{max}} / \mathrm{MPa}$ & $\sigma_{\text {nom }} / \mathrm{MPa}$ & $K_{t}$ & $K_{f}$ \\
\hline 0 (no hole) & 358.5 & 65.1 & 5.51 & - \\
8 & 274.8 & 71.8 & 3.83 & 3.75 \\
10 & 258.7 & 73.6 & 3.51 & 3.46 \\
14 & 238.0 & 77.3 & 3.08 & 3.05 \\
18 & 225.6 & 81.3 & 2.77 & 2.75 \\
22 & 218.1 & 85.4 & 2.55 & 2.54 \\
\hline
\end{tabular}

diameters. The maximum principal stress decreases with the increase of the hole diameter, but the decrease tendency slows down gradually. Similarly, $K_{\mathrm{t}}$ and $K_{\mathrm{f}}$ show the same trend. This can be attributed to the fact that the plastic region appears only in a small range near the crack tip, and the increase of the hole diameter will be of little significance after reaching a certain extent. In addition, excessive increase of the hole diameter will easily weaken the section stiffness and result in strength damage. Considering the balance of crack arrest effect and weakening effect, the stop-hole diameter was taken as $14 \mathrm{~mm}$.

The maximum principal stress contour results of numerical model with $14 \mathrm{~mm}$ hole are shown in Figure 5. It is obvious that new stress concentration appears at the edge of stop hole, making the position become the potential new crack initiation point. Figure 6 depicts the maximum principal stress distribution along the thickness of the hole at the minimum section of the crack arrest hole. The edge of the crack arrest hole is all in a relatively high stress state. From the perspective of the trend, it is evidenced that new fatigue cracks are prone to generate at the middle of the hole edge and further develop.

2.3.3. Level of Pretightening Force. The maximum principal stresses of different pretightening force levels were plotted in Figure 7. The pretightening force of $30 \mathrm{kN}$ is selected because the maximum principal stress is at the lowest level in this condition. The corresponding stress nephogram in Figure 8 indicates that the main stress distribution of the hole has changed significantly after the addition of high-strength bolt. The original tensile area around the edge of hole that is liable to suffer fatigue cracking has become a compressionoriented area. At the same time, the other side of the hole turns into a tension-oriented area, which has maximum tensile stress at the surface of steel plates. The reason is that when the specimen is subjected to tensile action, the crack will produce relative displacement, but the pressure generated between the surface of the steel plate and the bolt gasket prevents the crack growth. Figure 9 presents the trend of stress along the thickness of the hole under a preload of $30 \mathrm{kN}$. It can be seen from the chart that the stress at the smallest section of the crack arrest hole is significantly reduced, and the tension area of about $1.5 \mathrm{~mm}$ near the surface is even converted into compressive zone. The stress at the hole edge is reduced to nearly $82.6 \%$ of that of the only stophole model and, furthermore, the stress at the surface of steel plate is down by approximately 103\% (from tensile stress to compressive stress). It can be concluded that high-strength bolt stop-hole method possesses the better crack arrest behavior than only stop-hole method.

2.3.4. Size of CFRP Patch. To determine the optimal size of the CFRP patch, sizes (width $\times$ length) of $30 \mathrm{~mm} \times 50 \mathrm{~mm}$, $40 \mathrm{~mm} \times 50 \mathrm{~mm}, 50 \mathrm{~mm} \times 50 \mathrm{~mm}$, and $60 \mathrm{~mm} \times 50 \mathrm{~mm}$ were simulated and calculated, respectively. Figure 10 shows that, with the increase of the width of the CFRP patch, the maximum principal stress of the steel plate decreases but not obviously. This suggests that a width of $40 \mathrm{~mm}$ is sufficient to control the stress at the crack. However, considering the possible defects during the pasting process, a width of $50 \mathrm{~mm}$ was selected finally. The numerical results demonstrate that the stress distribution of CFRP is mainly located in the range of the stop hole around the crack, which entails that a length of $50 \mathrm{~mm}$ is sufficient if the CFRP strips and steel plate are ideally bonded. However, tests showed that debonding occurred at the beginning of the cyclic load by using $50 \mathrm{~mm} \times 50 \mathrm{~mm}$ CFRP patch. In order to provide more adhesive anchoring area, the CFRP length of the patch was extended to $250 \mathrm{~mm}$ [23].

The principal stress distributions of steel plate and $50 \mathrm{~mm} \times 250 \mathrm{~mm}$ CFRP patch are shown in Figure 11 . Compared with Figure 5, the maximum principal stress of the CFRP repaired model is $81.9 \mathrm{MPa}$, which is only $34.4 \%$ that of the single stop-hole repaired model. But the degree of reduction is smaller than that of the reinforcement method of high-strength bolt. Combined with Figure 12, the section stiffness of the steel plate has a sudden change at the notch crack, which increases the load stress of the adhesive layer here, thereby increasing the bearing capacity of CFRP. The single-layer CFRP has stress concentration at the crack, and the stress reaches $328.7 \mathrm{MPa}$. It is proved that pasting CFRP cloth can effectively reduce the partial load of the damaged section by increasing the structural rigidity, thereby increasing the fatigue life of the damaged steel plates.

\section{Experimental Program}

3.1. Process of Strengthening Test. Four types of specimens, (1) specimens without repairing, as control specimens for comparison, (2) specimens repaired by only the stop-hole method, (3) specimens repaired by the high-strength bolt stop-hole method, and (4) specimens repaired by highmodulus CFRP strips, were proposed in this research. Each group includes 3 steel plates.

To simulate the initial damage, all specimens were precracked prior to being repaired. Considering the crack uniformity, precision control, and practical maneuverability, $\mathrm{CNC}$ wire-cutting machine was finally chosen to produce the cracks. The crack length was set to $14 \mathrm{~mm}$, as shown in Figure 13; afterwards, the cracked steel plates needed to be strengthened. For various repair groups, stop holes were drilled at the crack tips with a hole of $14 \mathrm{~mm}$ in diameter. In particular, M12 high-strength (grade 12.9) bolts were tightened into stop holes and gaskets of $19 \mathrm{~mm}$ in diameter were used for high-strength bolt repair group. Then torque wrench was employed to apply $30 \mathrm{kN}$ pretightening force to 


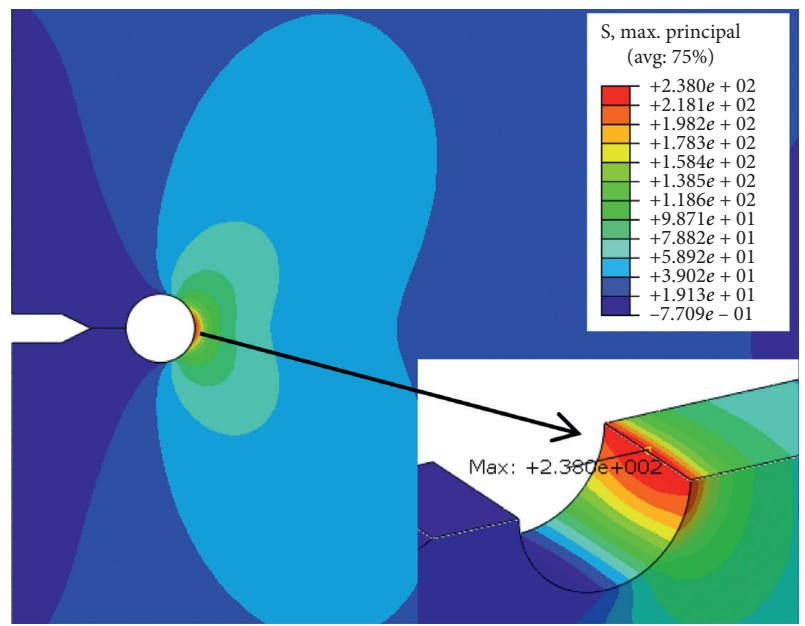

FIgURE 5: Maximum principal stress distribution.

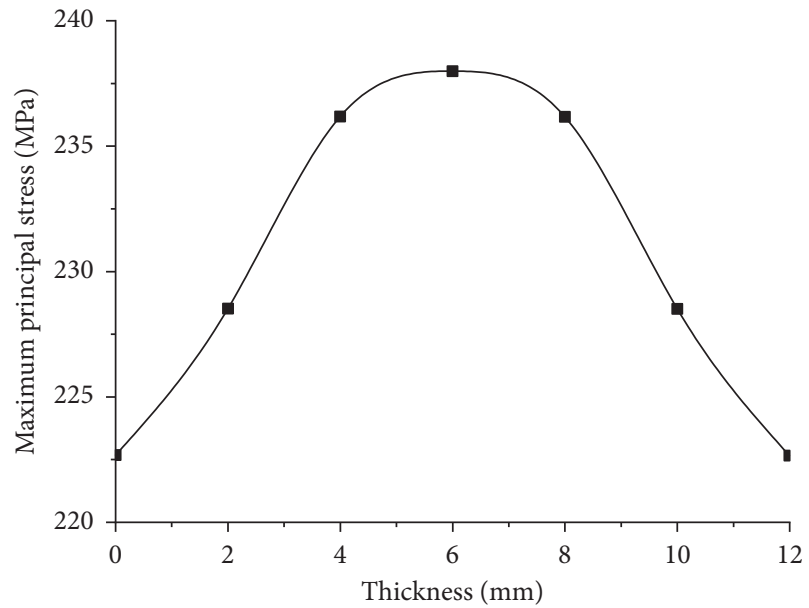

Figure 6: The trend of principal stress along the thickness of the hole under the preload.

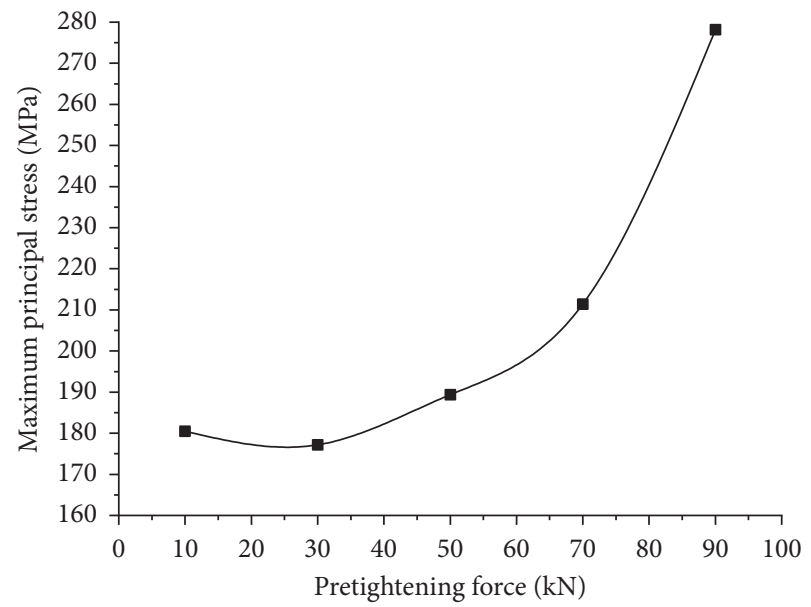

FIGURE 7: The principal stress of steel plate under various preloads.

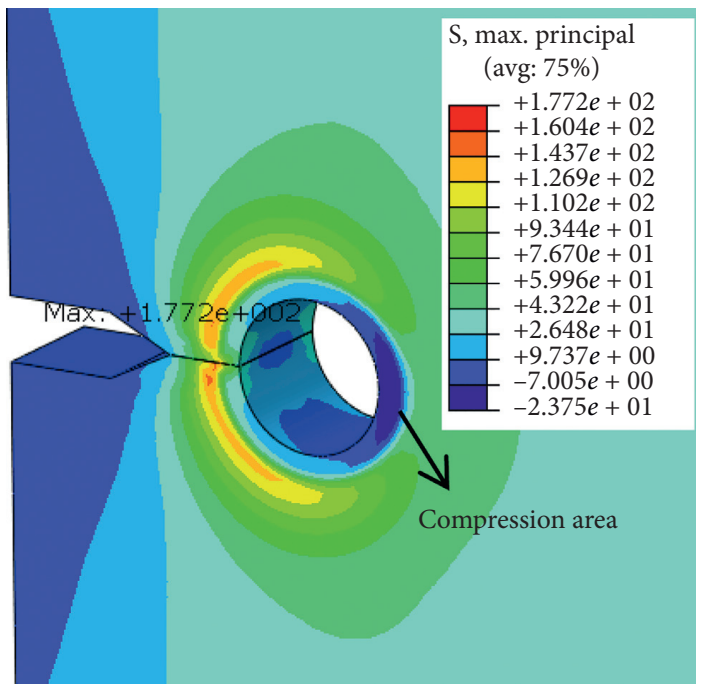

FIGURE 8: The principal stress of model with $30 \mathrm{kN}$ preload (MPa).

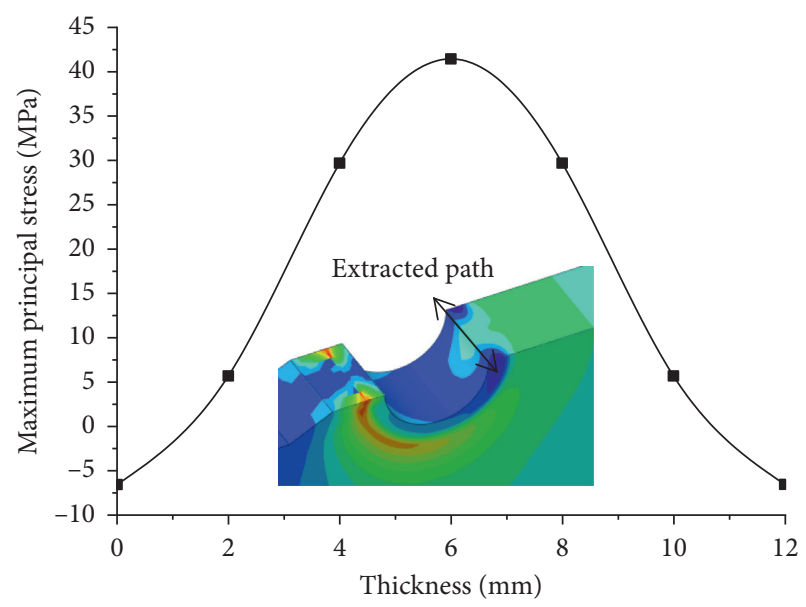

FIGURE 9: The trend of stress along the thickness of the hole under the preload.

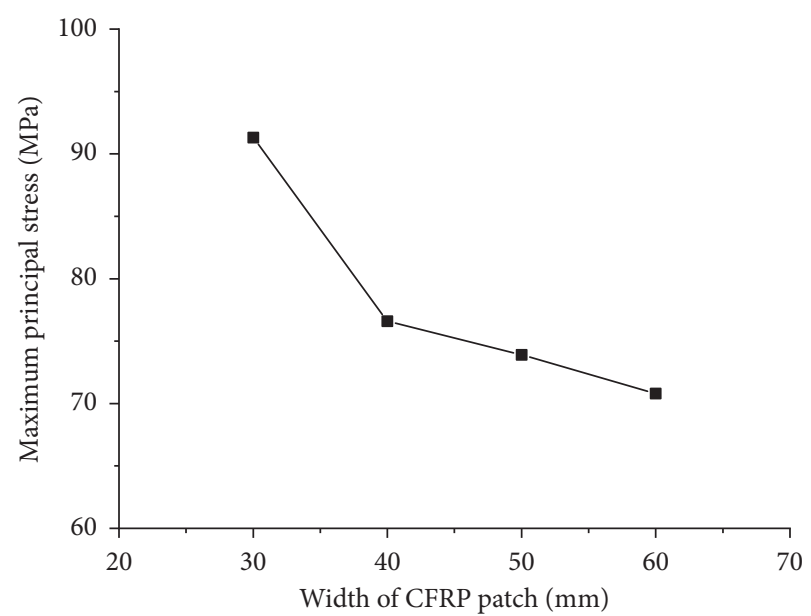

FIGURE 10: Maximum principal stress of different CFRP widths. 


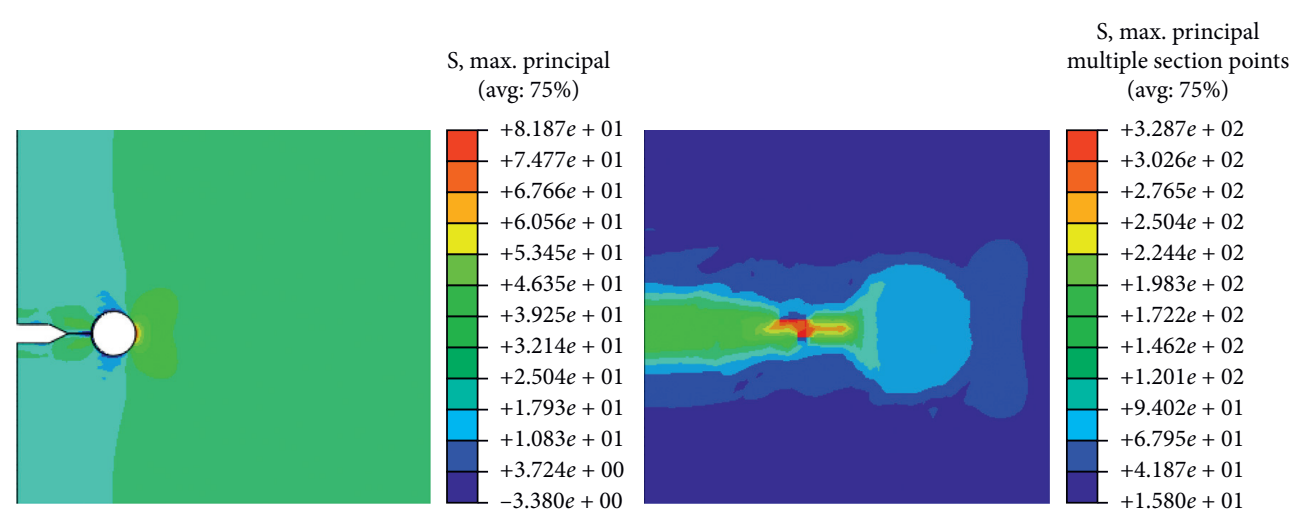

FIgURE 11: Stress contour of steel plate and CFRP patch (MPa).

the bolts, as illustrated in Figure 14; with regard to the highmodulus CFRP repair group, the carbon fiber strips were cut into the size of $250 \mathrm{~mm}$ long and $50 \mathrm{~mm}$ wide. The designed bonding area of steel plates was pretreated with grinding machine to increase surface roughness so that CFRP strips can be well pasted by structural adhesive. After pasting the CFRP strips on double sides of steel plates, the specimens were cured at room temperature for more than seven days until the adhesive reached the required strength. The specific fabrication of specimens in Group 4 followed the steps shown in Figure 14.

3.2. Test Setup and Instrumentation. All the fatigue tests were performed in a static/fatigue servo hydraulic machine named MTS647 Test Frame System. As depicted in Figure 15 , the specimens were loaded symmetrically at the middle point. The clamping area of the upper and lower clamps was $100 \mathrm{~mm} \times 126 \mathrm{~mm}$. Two ends of the test steel plates were gripped in the lower end and upper head, and the load was applied by the upper-end actuator.

Before the fatigue test, all specimens were loaded statically to $60 \mathrm{kN}$ in tension and then unloaded to zero to check the working condition of strain gauges and verify the reliability of finite element analysis results. Afterwards, the tension-tension fatigue tests were performed using constant amplitude sinusoidal loading cycles with a load frequency of $10 \mathrm{~Hz}$ and a stress ratio $R=0.1\left(R=\sigma_{\min } / \sigma_{\max }\right)$. It should be noted that bridge members are usually subjected to stress ratio around 0.1 because of the influence of heavy dead load. The maximum load was around $50 \%$ of steel tensile yield load. In order to improve the test loading efficiency, the design load amplitude of the test was relatively larger. The applied cycling load ranges for each specimen are shown in Table 3.

For the purpose of monitoring strain distribution near the fatigue source on the steel plates and crack propagation during the fatigue loading, two strain rosettes and four strain gauges were placed at the same position for Group 1, Group 2, and Group 3, respectively. Due to the constraint effect of strengthening CFRP strips, only four strain gauges were attached to the steel plates as shown in Figure 16(d). However, the first strain rosette is far away from the crack or stop-hole tip; the strain gauge at the crack or crack stop (about $2 \mathrm{~mm}$ from the center of the strain gauge to the edge) was added to the unstrengthened group (Group 1) and the stop-hole repair group (Group 2), as shown in Figures 16(a) 16(b). The distances between each group of strain gauges and the edge of steel plate are also shown in the figure. During the time that the crack propagated to a certain position, the placed strain gauge would emerge a sharp change, so that the crack growth with fatigue cycles can be recorded. The position of the strain rosette was taken as the measuring point of the nominal stress for Group 1, Group 2, and Group 3, while the strain gauge $60 \mathrm{~mm}$ away from the edge of the steel plate is used as the nominal stress measurement point. When the fatigue crack reached the measured point $90 \mathrm{~mm}$ away from the edge of steel plate, it was regarded as complete fatigue failure of specimens. Continuous sampling and dynamic monitoring are utilized in the test process.

\section{Results and Discussion}

4.1. Comparison of Static Test and FEM. Figure 17 presented the typical load-stress relationships of the four groups under static load. During the static load process, the measured stress was calculated by Hooke's law, since the structure belongs to the linear elastic stage. It was obvious that numerical results were nearly in accordance with the experimental ones, which suggested that the finite element models can correctly simulate the stress distribution of the specimen.

4.2. Failure Mode Analysis. The typical fatigue crack growth behavior of all specimens under the cycling loading was depicted in Figure 18; with the increase of the number of fatigue cycles, the fatigue cracks continued to develop along the direction perpendicular to applied tensile stress. For unrepaired group, the measured stress amplitude changed significantly after a few fatigue cycles. The fatigue crack initiations of specimens 1-1, 1-2, and 1-3 were triggered at the crack front, while the fatigue source originated from the edge of hole where stress concentrated for other groups; the findings of this experiment showed the similar way with previous finite element results. Certainly, the fatigue crack 


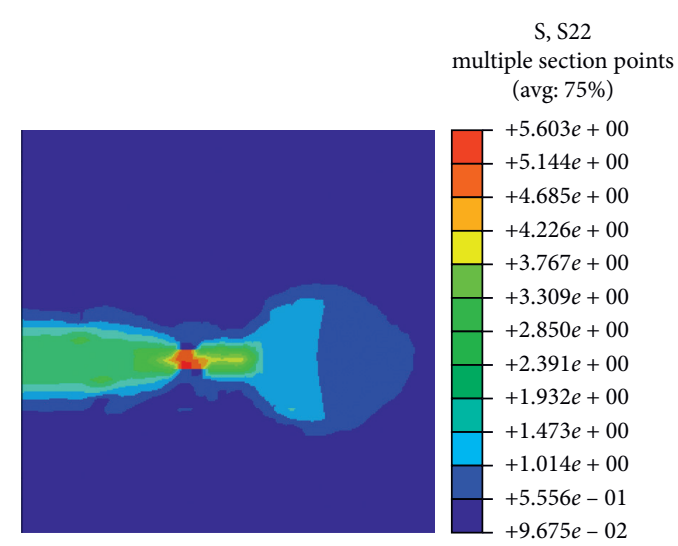

(a)

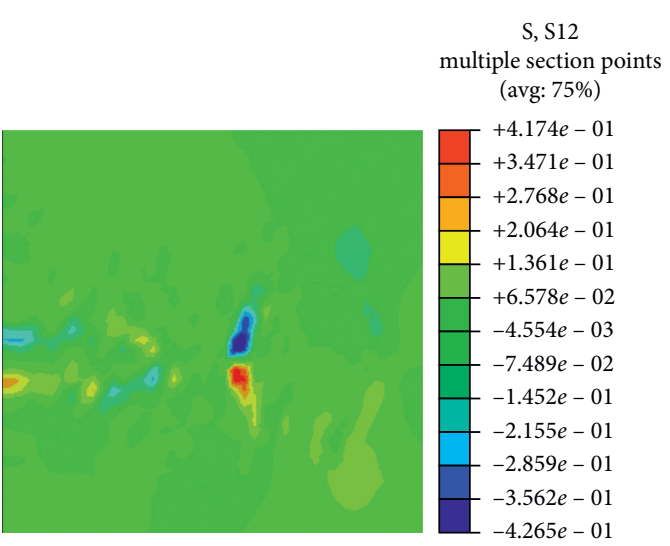

(b)

Figure 12: Adhesive layer stress of high-elastic-modulus CFRP paste repair. (a) Normal stress. (b) Shear stress.
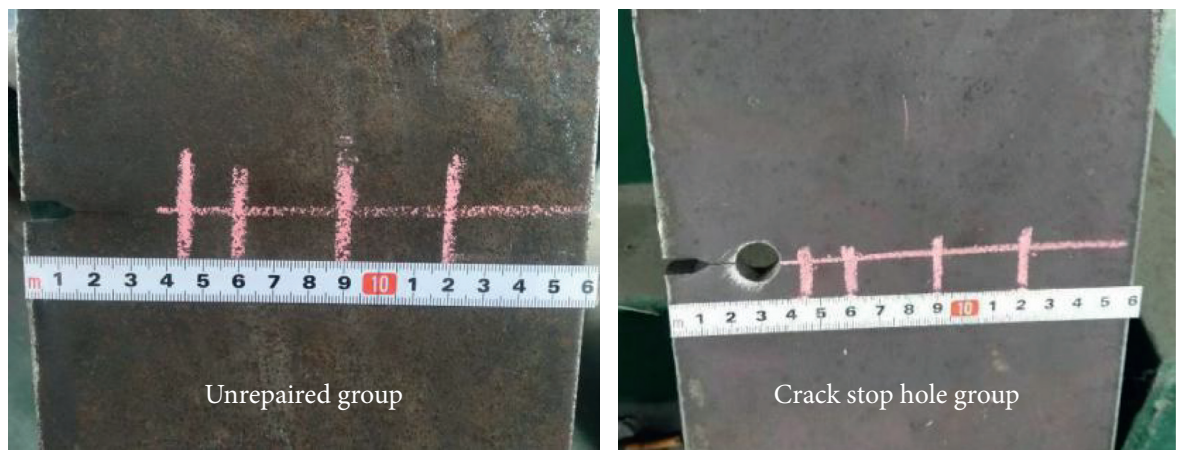

FIGURE 13: Unrepaired group and crack stop-hole group.
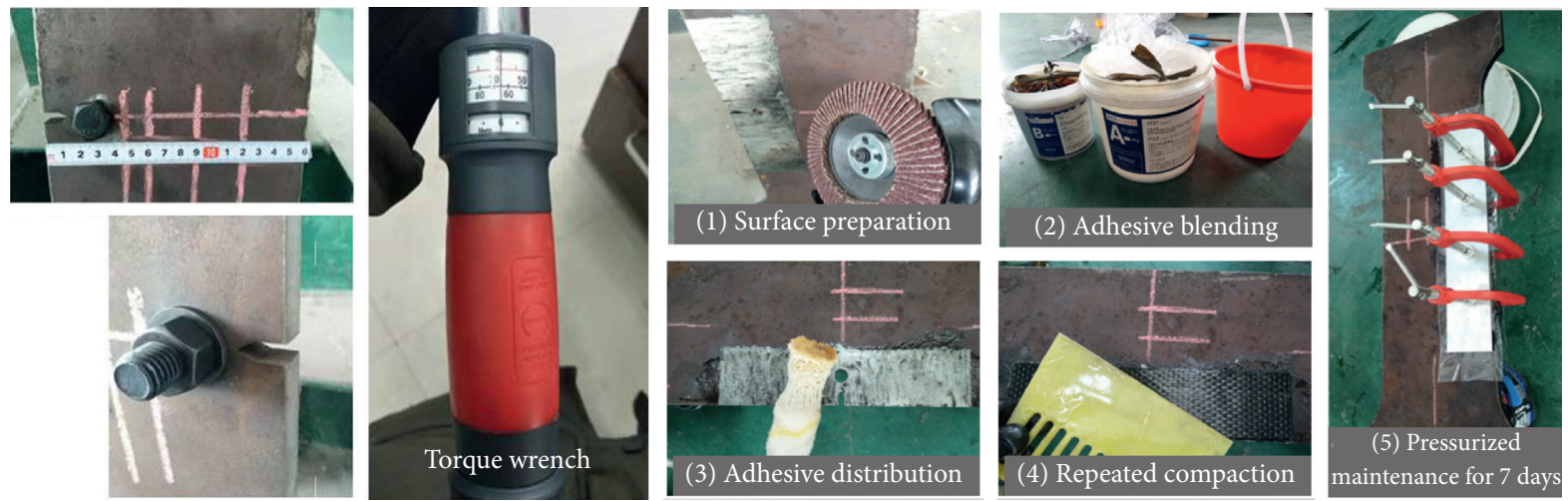

FIGURE 14: High-strength bolt repair group and CFRP repair group.

growth of the repaired specimens was obviously delayed due to the elimination of crack tip.

In particular, for Group 3, the washers and nuts suffered from fatigue cracking firstly under the action of friction due to the cumulative damage, as shown in Figures 19(a) 19(b). It is a fact that the crack point was located at the notch gab, where section stiffness had an abrupt change; thus, stress concentration appeared. Subsequently the preload of highstrength bolt failed, the crack arrest mechanism of highstrength bolts degenerated into a single stop-hole mechanism, and stress redistribution occurred around the hole.
Therefore, the failure finally occurred at the minimum section of the stop hole, which was the same as Group 2. However, the washers or nuts of tested specimen 3-3 were not damaged, and the relative slip between the washers and the steel plate was obvious at an early stage, indicating that the loss of pretightening force happened, as shown in Figure 19(c), so its fatigue life did not reach the expected level. The failure of 3-3 is probably due to the large stress amplitude and the insufficient friction caused by the deficiency of the pretightening force. This situation should be avoided during actual on-site repairing, and a certain 


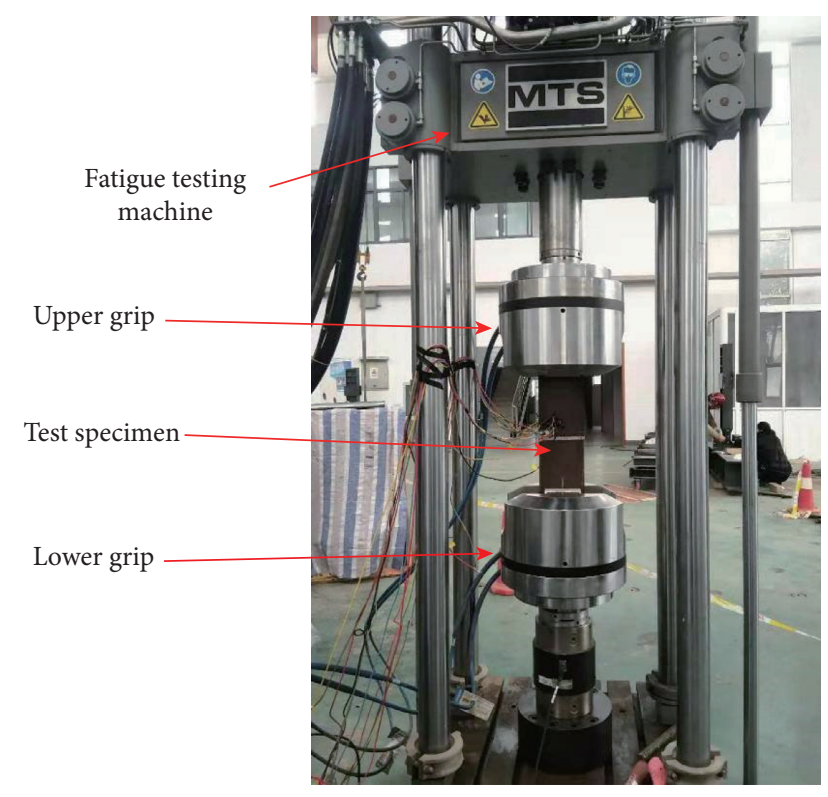

Figure 15: Fatigue test set-up.

TABle 3: Summary of load cases of test specimens.

\begin{tabular}{lcc}
\hline Strengthening method & Specimen & Load range $(\mathrm{kN})$ \\
\hline \multirow{2}{*}{ Unrepaired (Group 1) } & $1-1$ & $16.7 \sim 166.7$ \\
& $1-2$ & $19.4 \sim 194.4$ \\
& $1-3$ & $22.2 \sim 222.2$ \\
\hline \multirow{2}{*}{ Only stop-hole (Group 2) } & $2-1$ & $16.7 \sim 166.7$ \\
& $2-2$ & $19.4 \sim 194.4$ \\
\multirow{2}{*}{ High-strength bolt stop-hole } & $2-3$ & $22.2 \sim 222.2$ \\
(Group 3) & $3-1$ & $16.7 \sim 166.7$ \\
& $3-2$ & $19.4 \sim 194.4$ \\
\multirow{2}{*}{ High-modulus CFRP (Group 4) } & $3-3$ & $22.2 \sim 222.2$ \\
& $4-1$ & $16.7 \sim 166.7$ \\
& $4-2$ & $19.4 \sim 194.4$ \\
& $4-3$ & $22.2 \sim 222.2$ \\
\hline
\end{tabular}

technological treatment (such as sandblasting and rust removal) can be also carried out on the contact surface of the steel plate and the bolt washer when necessary. For the high-modulus CFRP repairing group, the failure was attributed to the debonding of the interface between CFRP strips and steel plates, as shown in Figure 20. At the initial stage of fatigue loading, the CFRP strips can bear the force together with the steel plates, but, after a certain number of cycles, the end of the CFRP sheet debonded; then the high-elastic-modulus CFRP repair mechanism degenerated into the stop-hole repair mechanism. However, the test specimens 4-2 and 4-3 showed interfacial debonding shortly after the beginning of higher dynamic load, and the relative slip between CFRP strips and steel plates was obvious, indicating that the CFRP repairing failed at an early stage and its fatigue life did not reach the expected level, which should be avoided in the actual on-site repairing.

4.3. Fatigue Improvement and Crack Propagation. Table 4 presents a summary of the experimental program and test results, including the load range, measured stress amplitude, crack initiation life, total fatigue life, and its extension ratio. The crack initiation life refers to the number of fatigue cycles that a crack regenerates at the edge of the arrest hole, while the crack initiation life plus the life for the propagation of the crack to the length position of $a=90 \mathrm{~mm}$ is the total fatigue life. The efficiency of strengthening was evaluated for cracked specimens with the fatigue life extension ratio that represents the ratio of the crack initiation life of repaired specimens to that of the unrepaired specimens.

From the data in Table 4, it is clear that all the repaired specimens achieve significant enhancement of fatigue life. In addition, crack initiation life dominated the entire fatigue life for repaired specimens. It can be observed that the crack initiation life of the specimens can be extended by more than 20 times using the stop-hole repairing method. With respect to the stop-hole repairing method, the use of high-strength bolts showed a 9-time increase over that of the only stophole one. Particularly, the fatigue life of the specimen is obviously decreased due to the pretightening force failure of high-strength bolts. Nonetheless, it is still 4.7 times of that of the repair with only the stop hole. For the high-modulus CFRP strips repairing method, the fatigue life of the specimens is more than 8 times of that of the specimen repaired solely with the stop-hole repairing method. Similarly, the premature debonding failure of the CFRP-strengthened specimens led to the reduction of the fatigue life at the early stage. The fatigue life of specimens using CFRP strips extended 1.8 times compared to the stop-hole groups. However, too small pretightening force is prone to cause interface slippage, leading to early failure of pretightening force. The smaller CFRP patch length, the greater possibility of early debonding. So, the failure of pretightening force and early failure of CFRP strips should be avoided during practical strengthening projects.

The initial crack length of the nonrepaired group (Group 1) is deemed as $30 \mathrm{~mm}$ (including the notch length), while the initial crack length of other groups is regarded as $37 \mathrm{~mm}$. In the test, the failures of strain gauge and visual inspection were used to judge the degree of crack growth, and the fatigue cycles of crack propagation to $45 \mathrm{~mm}, 60 \mathrm{~mm}$, and $90 \mathrm{~mm}$ were recorded, respectively, as shown in Figure 21. Group 4 was not considered due to the few experimental points. It can be seen that the fatigue crack growth trends of all groups were similar. The crack growth rate was accelerated after the formation of fatigue cracks, and, within 100,000 cycles, the specimens all were fatigue-loaded to failure. Moreover, the crack growth rate in the latter stage was higher than that in the former stage, indicating that fatigue damage was accelerated in the latter stage. It can be concluded that although crack stop hole and high-strength bolts repairing can delay the initiation of fatigue crack again, it has little influence on the propagation rate after crack initiation. Therefore, it is necessary to avoid the failure of crack arrest mechanism and fatigue cracking again in actual repair.

\section{Fatigue Performance on Repaired Specimens with S-N Method}

The test results were compared and analyzed with the relevant fatigue strength categories curves in the codes of various 


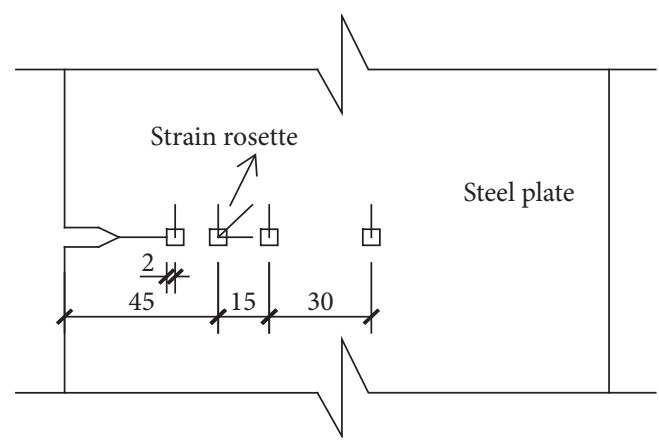

(a)

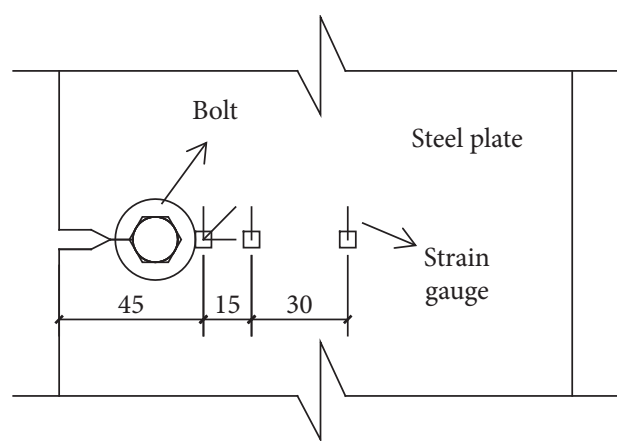

(c)

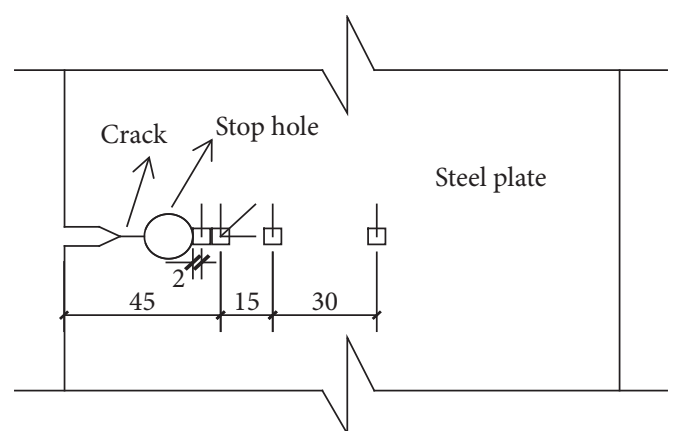

(b)

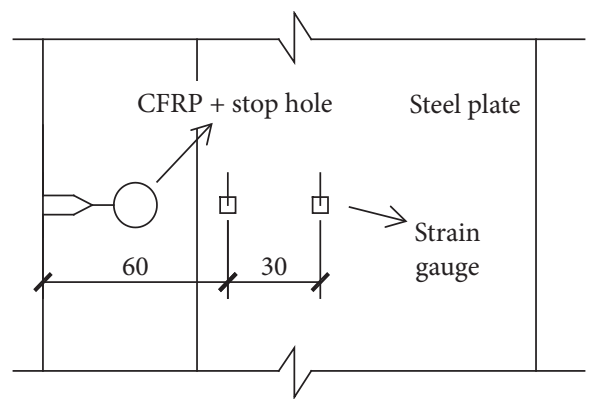

(d)

FIGURE 16: Locations of strain gauges on specimens for crack detection (mm). (a) Unstrengthened group. (b) Stop-hole repair group. (c) High-strength bolt stop-hole group. (d) High-modulus CFRP repair group.

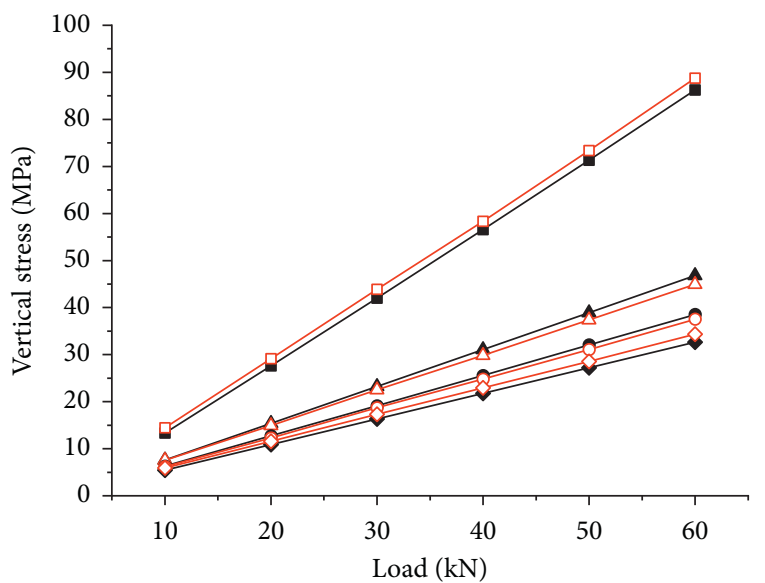

- FEM (2 mm away from crack tip)

$\rightarrow-$ Measured mean value

$\neg$ FEM (45 mm away from edge of steel plate)

$\triangle-$ Measured mean value

$\rightarrow$ FEM (60 $\mathrm{mm}$ away from edge of steel plate)

- - Measured mean value

- FEM (90 mm away from edge of steel plate)

$\checkmark$ Measured mean value

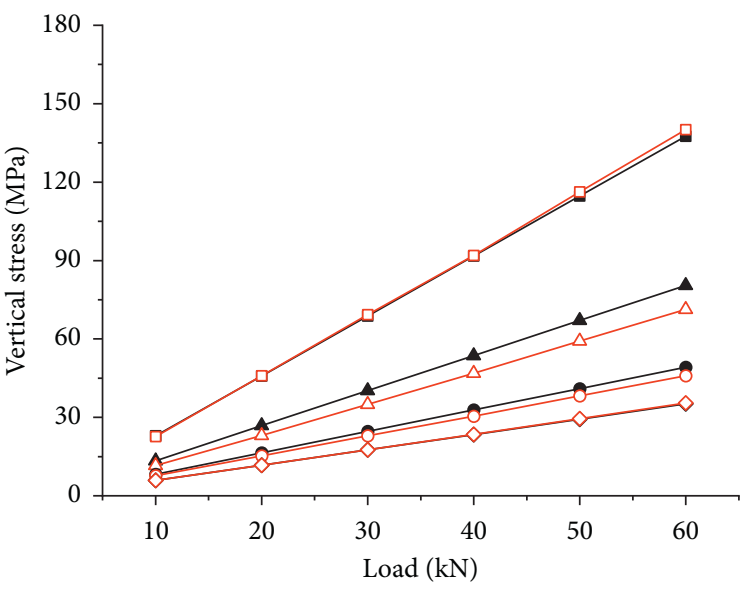

- $\operatorname{FEM}(2 \mathrm{~mm}$ away from crack tip)

$\rightarrow \square$ Measured mean value

ـ FEM (45 $\mathrm{mm}$ away from edge of steel plate)

$\triangle-$ Measured mean value

$\rightarrow$ FEM (60 mm away from edge of steel plate)

- - Measured mean value

- FEM (90 mm away from edge of steel plate)

$\diamond$ Measured mean value

(a)

(b)

Figure 17: Continued. 


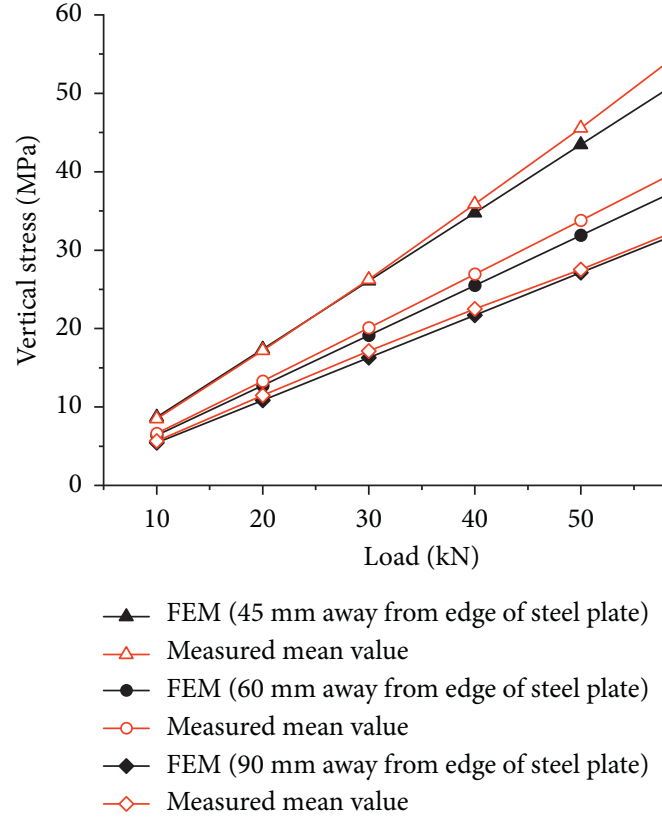

(c)

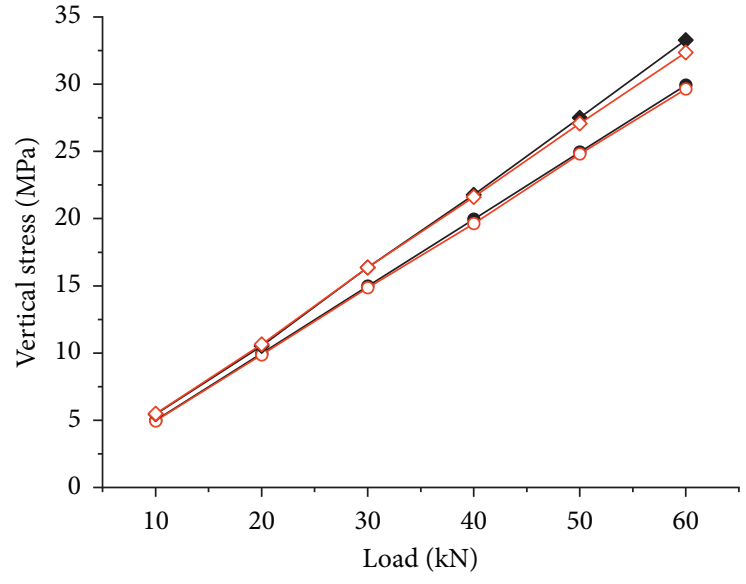

- $\operatorname{FEM}(60 \mathrm{~mm}$ away from edge of steel plate)

$\multimap$ Measured mean value

$\multimap$ FEM (90 mm away from edge of steel plate)

$\neg$ Measured mean value

(d)

Figure 17: Comparison of experimental results and FEM calculated values. (a) Group 1. (b) Group 2. (c) Group 3. (d) Group 4.
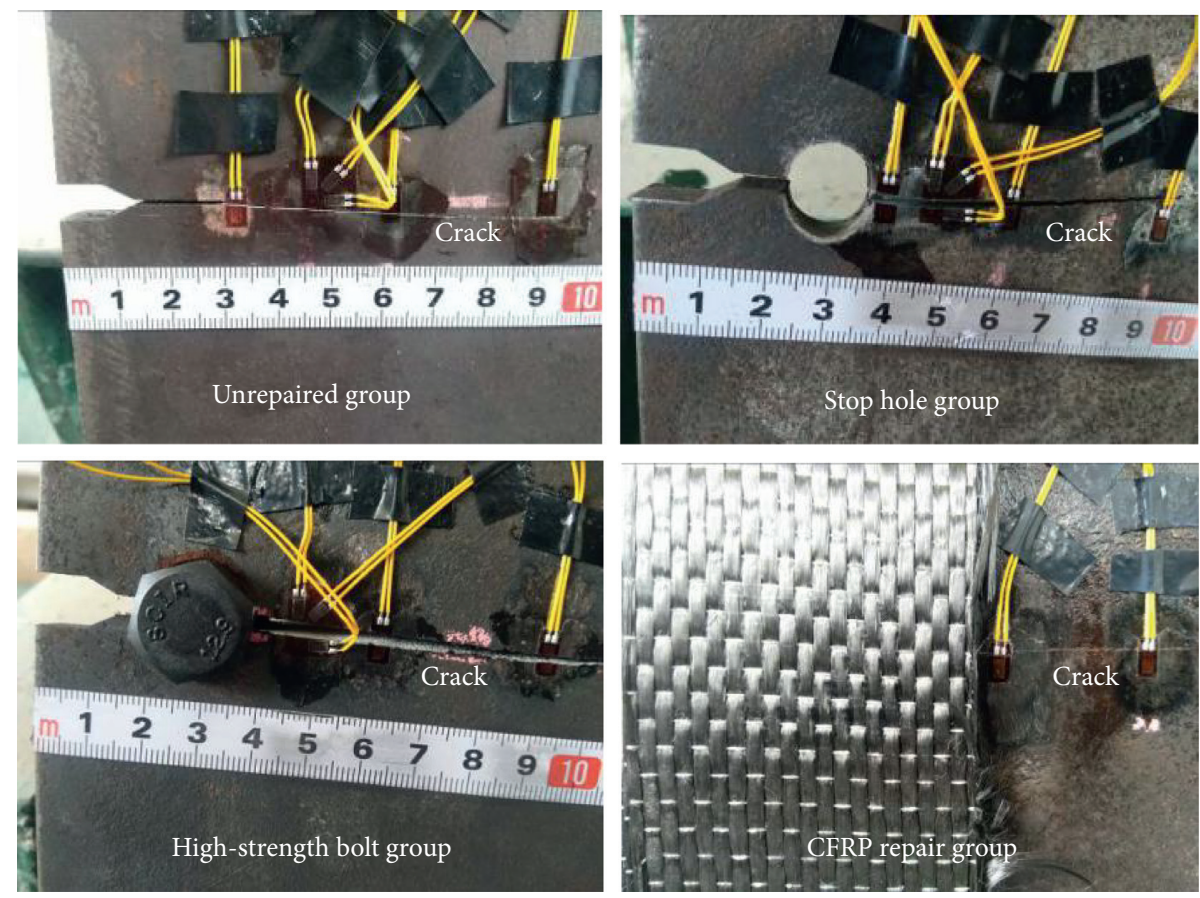

Figure 18: Typical fatigue cracking of specimens.

countries [24-27]. For fatigue detail of sheared or gas cut plates, Eurocode BS EN1993-1-9 Fatigue strength class [2005] is classified as $140 \mathrm{MPa}$ or $125 \mathrm{MPa}$ according to whether the edge is ground. The given fatigue detail is defined as category $\mathrm{C}$ by British and Japanese fatigue codes. Although the American code does not specify this detail category, category A in AASHTO can be referred in the assessment according to the base metal with rolled or cleaned surfaces and flame-cut edges.
Figure 22 illustrates a comparison of fatigue test data against fatigue strength categories of the various specifications. As can be seen in the figure, the differences in fatigue curves for this detail are relatively small. The fatigue strength of the stop-hole group was lower than the requirements of national codes, which further indicated that this method could not effectively prevent the fatigue crack from respreading for a long time when repairing the steel plates 


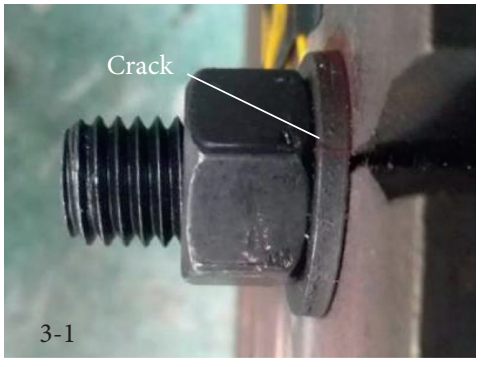

(a)

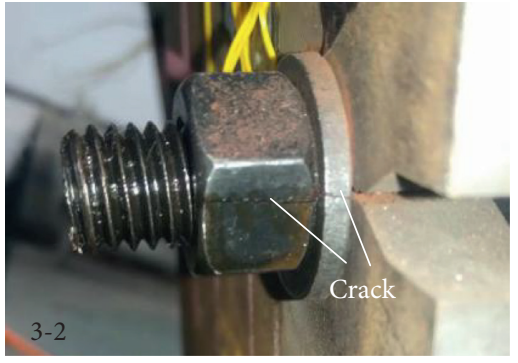

(b)

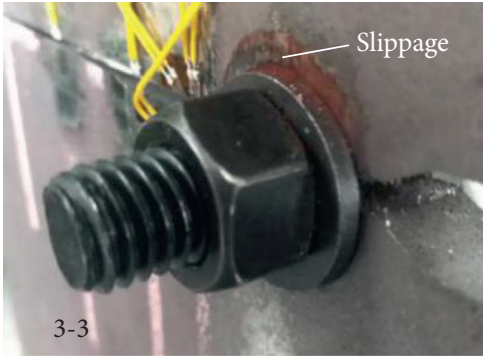

(c)

Figure 19: Observation of Group 3 during fatigue test. (a) Fatigue crack of washer. (b) Fatigue crack of washer and nut. (c) Slippage of washer.
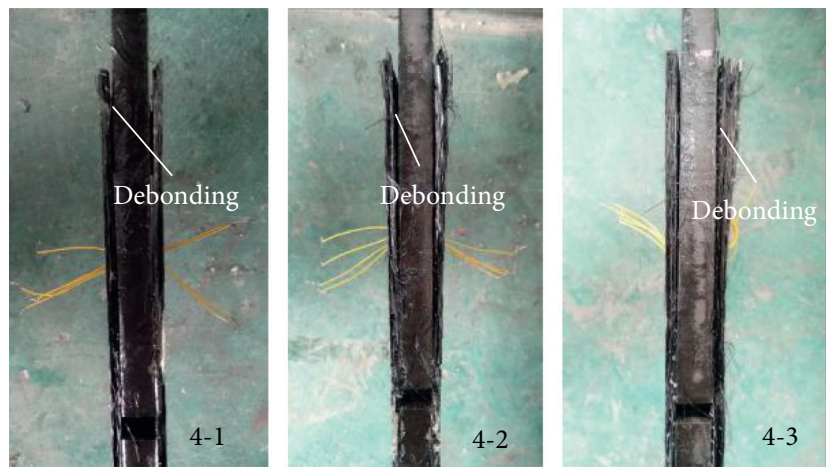

FIgURE 20: CFRP debonding of Group 4 during fatigue test.

TABLE 4: Fatigue test results of specimens.

\begin{tabular}{|c|c|c|c|c|c|c|}
\hline $\begin{array}{l}\text { Strengthening } \\
\text { method }\end{array}$ & $\begin{array}{c}\text { Test } \\
\text { specimen }\end{array}$ & $\begin{array}{l}\text { Load amplitude } \\
(\mathrm{kN})\end{array}$ & $\begin{array}{l}\text { Measured stress } \\
\text { amplitude }(\mathrm{MPa})\end{array}$ & $\begin{array}{c}\text { Crack initiation life } \\
\left(10^{4} \text { times }\right)\end{array}$ & $\begin{array}{c}\text { Total fatigue life } \\
\left(10^{4} \text { times }\right)\end{array}$ & $\begin{array}{c}\text { Fatigue life } \\
\text { extension ratio }\end{array}$ \\
\hline \multirow{3}{*}{ Unrepaired } & $1-1$ & 150 & 157 & 1.0 & 8.2 & 1 \\
\hline & $1-2$ & 175 & 180 & 0.5 & 4.6 & 1 \\
\hline & $1-3$ & 200 & 204 & 0.4 & 3.7 & 1 \\
\hline \multirow{3}{*}{ Only stop-hole } & $2-1$ & 150 & 210 & 20.5 & 25.2 & 20.5 \\
\hline & $2-2$ & 175 & 230 & 13.5 & 17.1 & 27 \\
\hline & $2-3$ & 200 & 288 & 5.0 & 8.1 & 12.5 \\
\hline \multirow{3}{*}{$\begin{array}{l}\text { High-strength bolt } \\
\text { stop-hole }\end{array}$} & $3-1$ & 150 & 185 & 178.5 & 180.7 & 178.5 \\
\hline & $3-2$ & 175 & 201 & 139.5 & 141.9 & 279 \\
\hline & $3-3^{*}$ & 200 & 231 & 23.5 & 26.6 & 58.75 \\
\hline \multirow{3}{*}{ High-modulus CFRP } & $4-1$ & 150 & 197 & 172.7 & 175.7 & 172.7 \\
\hline & $4-2^{*}$ & 175 & 228 & 20.0 & 24.7 & 40 \\
\hline & $4-3^{*}$ & 200 & 250 & 13.0 & 18.2 & 32.5 \\
\hline
\end{tabular}

${ }^{*}$ Washer slippage occurred in the 3-3 specimen, and CFRP debonding failures occurred in the 4-2 and 4-3 specimens.

with initial cracks. But it was often used as a temporary crack arrest measure, which was consistent with the relevant research results [5]. By contrast, the fatigue strength of the specimens is slightly increased when strengthened by highstrength bolts and high-modulus CFRP strips, respectively, except for those test specimens that failed early. Nonetheless, they were still higher than the specimens repaired by only stop-hole method. It was obvious that the high-strength bolt stop-hole repair group and the CFRP repair group were significantly higher than category A of AASHTO, indicating that the use of high-strength bolts and high-modulus CFRP strips on the stop-hole method could possess excellent fatigue resistance. Additionally, the fatigue strengths of two repaired specimen types were quite close; thus, the 


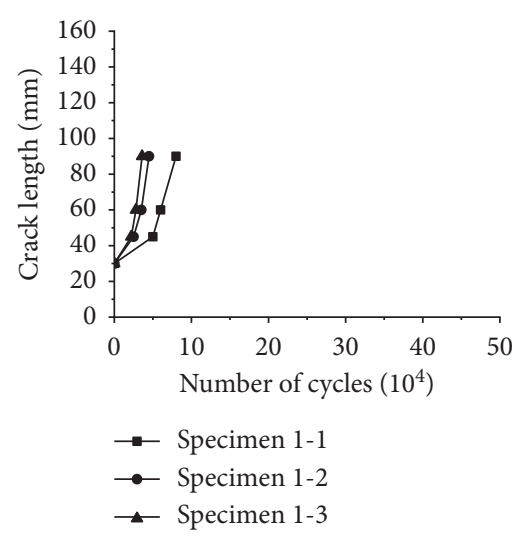

(a)

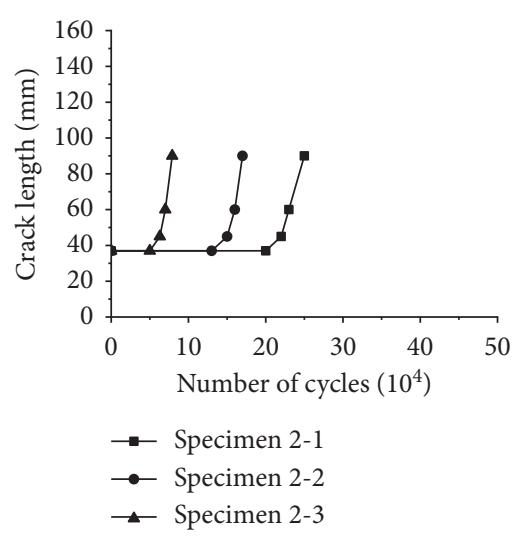

(b)

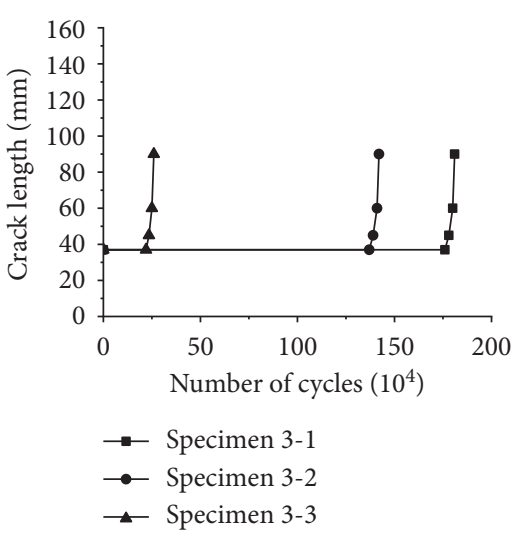

(c)

Figure 21: The curve of crack propagation. (a) Group 1. (b) Group 2. (c) Group 3.

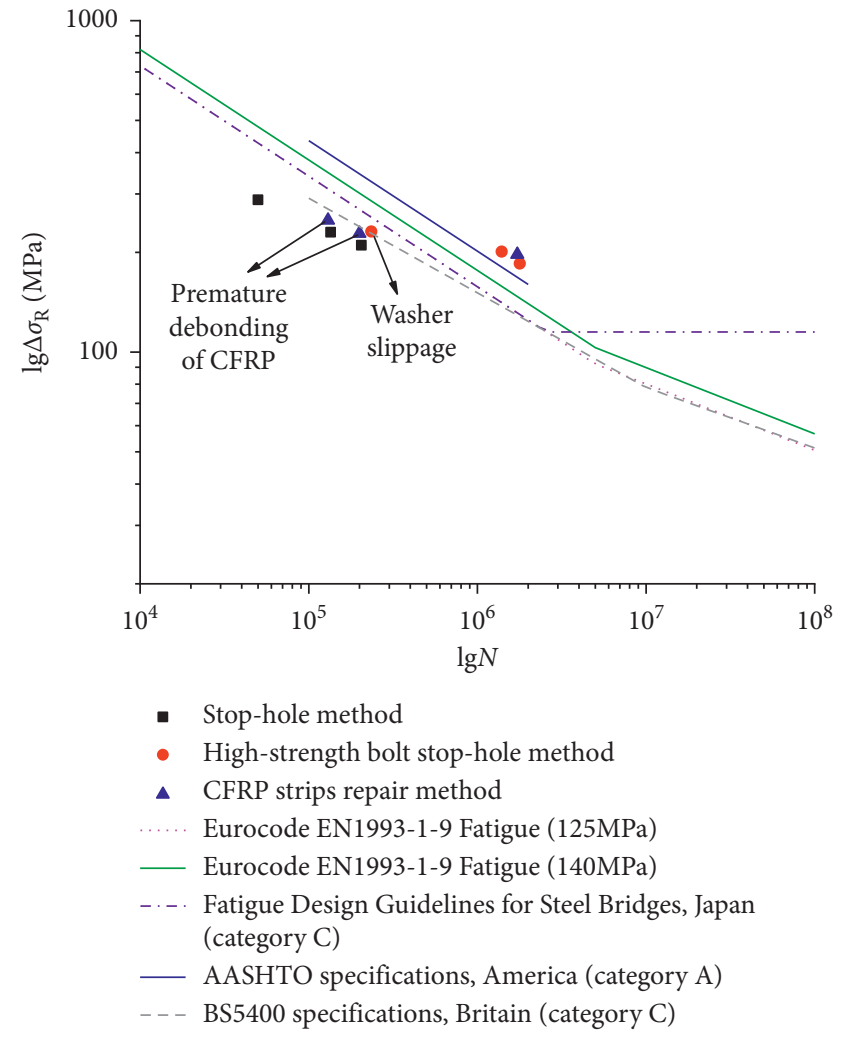

Figure 22: Fatigue repair test results and S-N curves.

appropriate reinforcement scheme can be selected according to the different site conditions.

\section{Conclusion}

This paper focused on the comparative performance of unrepaired and repaired specimens. First, finite element models were established to analyze optimal repair parameters on stress distribution of cracked steel plates. Then, a total of 12 specimens were designed and tested under the fatigue loading cycles. Various repairing methods have been developed to investigate the fatigue improvement of cracked steel plates. The following conclusions can be drawn based on the limited numerical and experimental data:

(1) The finite element results showed that the larger the hole diameter, the smaller the stress concentration factor $\left(K_{\mathrm{t}}\right)$ and fatigue notch coefficient $\left(K_{\mathrm{f}}\right)$ by drilling holes. But new stress concentration point originated from the edge of hole. Considering the overweakening of the section rigidity, the hole diameter of $14 \mathrm{~mm}$ was proposed here. The addition of high-strength bolts and high-modulus CFRP strips, respectively, could effectively reduce the stress concentration of the hole edge to delay the crack initiation.

(2) The failure mode of the unrepaired specimens is characterized by the fracture propagated from the crack tip, while the fatigue source of specimens strengthened solely by stop-hole method originated from the edge of hole where stress concentrated. In terms of the high-strength bolt repair method, the gaskets and nuts suffered from fatigue cracking under the action of friction due to the cumulative damage. As noted for the CFRP-strengthened specimens, the typical debonding failure between steel plates and CFRP can be found after a certain number of fatigue cycles.

(3) The fatigue behavior of cracked steel plates is significantly improved by using different repairing methods. Compared to the reference specimens, fatigue life can be enhanced by more than 20 times by only using the stop-hole repairing method. In comparison with the cracked steel plates strengthened solely with stop hole, the application of highstrength bolts and high-modulus CFRP strips can prolong the fatigue life by 9 times and 8 times, respectively. Regarding the washer slipping and premature debonding of CFRP strips, they will reduce the repairing efficiency and should be avoided during on-site application. Moreover, it should be noted that the positive effectiveness of employing the highstrength bolts was slightly more than that of specimens using the high-modulus CFRP strips. 
(4) By comparing the experimental results with S-N curves of given fatigue detail, the use of stop-hole repair alone is not enough to satisfy the fatigue strength category specified by national standard, while the positive effect with the addition of high-strength bolts and highmodulus CFRP strips on fatigue-cracked steel plates has been confirmed. Furthermore, the repairing effectiveness of high-strength bolt stop-hole method and high-modulus CFRP method has reached or even slightly exceeded category A of AASHTO.

\section{Data Availability}

All the data included in this study are available upon request from the corresponding author.

\section{Conflicts of Interest}

The authors declare that they have no conflicts of interest.

\section{Acknowledgments}

The authors acknowledge the financial support from the Key Research Project of Guangdong Province of China (no. 2019B111106002), Tongji Architectural Design (Group) Co., Ltd, CSCEC-2020-Z-1: Research on Application of CFRP Composites in Civil Engineering and SHANGHAI CFRP Research Center Project 20DZ2253000: application of CFRP composites in Civil Engineering.

\section{References}

[1] J. W. Fisher and S. Roy, "Fatigue of steel bridge infrastructure," Structure and Infrastructure Engineering, vol. 7, no. 7-8, pp. 457-475, 2011.

[2] M. Goto, H. Miyagawa, and H. Nisitani, "Crack growth arresting property of a hole and Brinell-type dimple," Fatigue \& Fracture of Engineering Materialse Structures, vol. 19, no. 1, pp. 39-49, 1996.

[3] M. R. Ayatollahi, S. M. J. Razavi, and M. Y. Yahya, "Mixed mode fatigue crack initiation and growth in a CT specimen repaired by stop hole technique," Engineering Fracture Mechanics, vol. 145, pp. 115-127, 2015.

[4] H. Wu, A. Imad, N. Benseddiq, J. Tupiassú Pinho de Castro, and M. Antonio Meggiolaro, "On the prediction of the residual fatigue life of cracked structures repaired by the stophole method," International Journal of Fatigue, vol. 32, no. 4, pp. 670-677, 2010.

[5] J.-H. Choi and D.-H. Kim, "Stress characteristics and fatigue crack behaviour of the longitudinal rib-to-cross beam joints in an orthotropic steel deck," Advances in Structural Engineering, vol. 11, no. 2, pp. 189-198, 2008.

[6] P. Song and Y. L. Shieh, "Stop drilling procedure for fatigue life improvement," International Journal of Fatigue, vol. 26, no. 12, pp. 1333-1339, 2004.

[7] N.-Z. Chen, "A stop-hole method for marine and offshore structures," International Journal of Fatigue, vol. 88, pp. 4957, 2016.

[8] M. R. Ayatollahi, S. M. J. Razavi, and H. R. Chamani, "A numerical study on the effect of symmetric crack flank holes on fatigue life extension of a SENT specimen," Fatigue \& Fracture of Engineering Materials \& Structures, vol. 37, no. 10, pp. 1153-1164, 2015.
[9] Y. Yao, B.-H. Ji, and Z.-Q. Fu, "Optimization of stop-hole parameters for cracks at diaphragm-to-rib weld in steel bridges," Journal of Constructional Steel Research, vol. 162, Article ID 05747, 2019.

[10] M. Fanni, N. Fouda, M. A. N. Shabara, and M. Awad, "New crack stop hole shape using structural optimizing technique," Ain Shams Engineering Journal, vol. 6, no. 3, pp. 987-999, 2015.

[11] A. Murdani, C. Makabe, A. Saimoto, Y. Irei, and T. Miyazaki, "Stress concentration at stop-drilled holes and additional holes," Engineering Failure Analysis, vol. 15, no. 7, pp. 810-819, 2008.

[12] S. M. J. Razavi, M. R. Ayatollahi, C. Sommitsch, and C. Moser, "Retardation of fatigue crack growth in high strength steel S690 using a modified stop-hole technique," Engineering Fracture Mechanics, vol. 169, pp. 226-237, 2017.

[13] D. Duprat, D. Campassens, and M. Balzano, "Fatigue life prediction of interference fit fastener and cold worked holes," International Journal of Fatigue, vol. 18, no. 8, pp. 515-521, 1996.

[14] D. Uchida, "Fatigue strength evaluation of out-of-plane gusset welded joints repaired by bolting-stop-hole method," Mitsui Engineering \& Shipbuilding Technology, vol. 190, pp. 45-53, 2007, in Japanese.

[15] X.-L. Zhao and L. Zhang, "State-of-the-art review on FRP strengthened steel structures," Engineering Structures, vol. 29, no. 8, pp. 1808-1823, 2007.

[16] A. Hosseini, E. Ghafoori, M. Motavalli et al., "Development of prestressed unbonded and bonded CFRP strengthening solutions for tensile metallic members," Engineering Structures, vol. 181, pp. 550-561, 2019.

[17] M. D'Aniello, F. Portioli, and R. Landolfo, "Lap shear tests on hotdriven steel riveted connections strengthened by means of C-FRPs," Composites Part B: Engineering, vol. 59, pp. 140-152, 2014.

[18] L. Hu, P. Feng, and X.-L. Zhao, "Fatigue design of CFRP strengthened steel members," Thin-Walled Structures, vol. 119, pp. 482-498, 2017.

[19] P. Feng, L. Hu, X.-L. Zhao, L. Cheng, and S. Xu, "Study on thermal effects on fatigue behavior of cracked steel plates strengthened by CFRP sheets," Thin-Walled Structures, vol. 82, pp. 311-320, 2014.

[20] C. Wu, X.-L. Zhao, R. Al-Mahaidi, M. R. Emdad, and W. Duan, "Fatigue tests of cracked steel plates strengthened with UHM CFRP plates," Advances in Structural Engineering, vol. 15, no. 10, pp. 1801-1815, 2012.

[21] H. Nakamura, W. Jiang, H. Suzuki, K.-i. Maeda, and T. Irube, "Experimental study on repair of fatigue cracks at welded web gusset joint using CFRP strips," Thin-Walled Structures, vol. 47, no. 10, pp. 1059-1068, 2009.

[22] Z.-Q. Fu, B.-H. Ji, S.-H. Xie, and T.-j. Liu, "Crack stop holes in steel bridge decks: drilling method and effects," Journal of Central South University, vol. 24, no. 10, pp. 2372-2381, 2017.

[23] T. Chen, C. Yao, L. Hu, C. Huang, and X. Li, "Numerical analysis of central mixed-mode cracking in steel plates repaired with CFRP materials," Thin-Walled Structures, vol. 143, p. 106196, 2019.

[24] British Standards Institution, B. S. 5400, Steel, Concrete and Composite Bridges: Part 10: Code of Practice for Fatigue, British Standards Institution, London, UK, 1980.

[25] European Committee for Standardization (CEN), Eurocode 3, Part 1-9: Fatigue, European Committee for Standardization (CEN), Brussels, Belgium, 1993.

[26] AASHTO, LRFD Bridge Design Specifications, SI Units, AASHTO, Washington, DC, USA, 4rd Ed. edition, 2007.

[27] Japan Road Association, Fatigue Design Guidelines for Steel Highway Bridges, Japan Road Association, Chiyoda-ku, Japan, in Japanese, 2002. 